\title{
COMPETÊNCIA EM INFORMAÇÃO: CONEXÕES NO ENSINO DE FONTES DE INFORMAÇÃO
}

\author{
Elisa Cristina Delfini Corrêa ${ }^{1}$
}

\begin{abstract}
Resumo: Análise das possibilidades teóricas e práticas da aplicação de modelos de competência em informação (CoInfo) na disciplina de Fontes de Informação. Pesquisa de caráter aplicado, quanto aos procedimentos trata-se de pesquisa bibliográfica e documental, com análise comparativa entre a literatura sobre o tema e o plano de ensino da disciplina de Fontes de Informação oferecida no curso de Biblioteconomia da Universidade do estado de Santa Catarina em 2015. Possui também caráter empírico, sob o método de observação sistemática, por meio da aplicação de exercícios previstos no plano de ensino da disciplina, cujos dados permitiram apresentar o estado da arte inicial dos graduandos e o desenvolvimento de suas habilidades na busca, acesso e uso de fontes de informação durante a disciplina. Os resultados apontam para uma estreita relação entre a disciplina de Fontes de Informação e os modelos de CoInfo demonstrando a importância da utilização dos modelos na formação acadêmica fortalecendo o papel de mediação no desenvolvimento de habilidades para a busca, acesso e uso da informação.
\end{abstract}

Palavras-chave: Competência em Informação. Formação do bibliotecário. Fontes de Informação.

\section{INFORMATION LITERACY: CONNECTIONS IN THE EDUCATION OF SOURCES OF INFORMATION}

\begin{abstract}
Analysis of theoretical and practical possibilities of the application of models of information literacy in the discipline Information Sources. Research of applied character with bibliographical research and documentary research, with a comparative analysis between the literature on the subject and the teaching plan of the Information Sources discipline offered in the undergraduate course in Librarianship of the University of the State of Santa Catarina during the year 2015. It also has empirical character with application of exercises that allowed to present the state of the art of the undergraduates regarding the competence in information in the search, access and use of sources of information. The results point to a close relationship between the discipline and models of competence in information. The application of the exercises demonstrated the importance of the use of models in the academic formation to strengthen the role of mediation in the development of abilities for the search, access and use of information.
\end{abstract}

Keyword: Information Literacy. Librarian graduation. Information Sources.

\section{INTRODUÇÃO}

A formação profissional oferecida pelas universidades, especialmente as públicas, sofre com o descompasso consequente do desenvolvimento acelerado da sociedade e suas demandas constantes e rapidamente renovadas. Reformulações curriculares são processos que exigem pesquisa, intensos debates e negociações e passam por processos burocráticos em diferentes instâncias universitárias, muitas vezes demandando longo tempo para sua maturação, aprovação e finalmente implementação.

A sociedade, por sua vez, está em constante mutação e exige cada vez maior atualização de conteúdos para a formação profissional. Para tentar acompanhar esse crescimento, os docentes contam

\footnotetext{
1 Doutora em Sociologia Política pela Universidade Federal de Santa Catarina (UFSC). E-mail: elisacorrea61@gmail.com
} 
com a possibilidade de inserir temas atualizados nos conteúdos programáticos dos planos de ensino das disciplinas que ministram.

Essa realidade pode ser verificada nos cursos de graduação em Biblioteconomia oferecidos no Brasil em especial no que diz respeito à inclusão de assuntos contemporâneos e, no caso deste artigo, interessam temas dedicados à Competência em Informação (CoInfo), introduzidos no país no início dos $\operatorname{anos} 2000$.

A disciplina de Fontes de Informação oferece um cenário favorável para a aplicação desta temática, pois enfatiza o perfil educador do bibliotecário, capacitando-o para atuar tanto na mediação para o uso de fontes como também na orientação aos interagentes de unidades de informação (usuários e clientes) quanto ao desenvolvimento de habilidades para realizar buscas e acessar a informação a fim de assimilar e aplicar conteúdos para a construção do conhecimento individual e coletivo.

Assim, a CoInfo representa uma possibilidade teórico-prática de intervenção social do bibliotecário para a construção de uma sociedade melhor informada, mais autônoma e competente na busca, assimilação e uso crítico da informação.

O presente artigo apresenta uso teórico e prático dos conceitos e etapas da CoInfo na disciplina Fontes de Informação, buscando identificar conexões teórico-práticas entre o tema e a proposta da disciplina expressos em seu plano de ensino e, a partir da elaboração de exercícios práticos, aplicar e testar sua validade na formação do futuro bibliotecário.

Os dados para análise foram coletados durante o primeiro semestre do ano de 2015 quando a disciplina Fontes de Informação (72h/aula) foi ofertada para a quinta fase do curso de Biblioteconomia com habilitação em Gestão da Informação oferecido pelo Centro de Ciências Humanas e da Educação FAED - da Universidade do Estado de Santa Catarina - UDESC.

As hipóteses levantadas e testadas durante a pesquisa foram as seguintes:

a) A identificação e análise das conexões entre o tema e a disciplina deverão abrir caminhos para uma reflexão mais atualizada do papel do bibliotecário enquanto curador e mediador da informação com vistas a uma melhor compreensão de seu papel social também enquanto educador.

b) Estarão igualmente mais claras e evidentes que atividades o futuro profissional poderá executar a partir do aprendizado obtido a partir dessas conexões, no sentido de contribuir para o desenvolvimento de uma sociedade melhor informada e mais autônoma na busca, acesso e uso da informação. 
c) A aplicação dos modelos de Competência em Informação em sala com os alunos, deverá apontar de maneira prática a contribuição desta no desenvolvimento da disciplina, bem como darão subsídios concretos para a futura atuação dos acadêmicos no mundo do trabalho.

A metodologia utilizada para coleta e análise dos dados foi a pesquisa bibliográfica-documental. Pesquisa bibliográfica com a finalidade de identificar pontos em comum entre o tema Competência em Informação e as propostas didático-pedagógicas do plano de ensino da disciplina em questão, com a finalidade de avaliar a aplicabilidade de seus conceitos e atividades no desenvolvimento das disciplinas. A análise crítica documental e comparativa do plano de ensino com a literatura permitiu identificar pontos em comum e possibilidades de aplicação do tema de maneira teórica e prática na disciplina.

Após a análise bibliográfica e documental foram aplicados exercícios em sala de aula previstos no plano de ensino e explicitamente elaborados para conhecer o estado inicial e o desenvolvimento da competência em informação dos alunos durante o período da disciplina.

O presente artigo apresenta o referencial teórico que deu base à pesquisa, uma descrição dos procedimentos metodológicos utilizados para coleta e análise dos dados e, por fim, apresentação e discussão dos resultados obtidos.

\section{REVISÃO DE LITERATURA}

Os conceitos mais importantes para o desenvolvimento da presente pesquisa giram em torno das temáticas competência em informação no ensino universitário e ensino de fontes de informação e são aqui apresentados à luz da literatura específica da área de Ciência da Informação e Biblioteconomia.

\subsection{COMPETÊNCIA EM INFORMAÇÃO}

O conceito de competência, entendido como a "capacidade de ativar e de usar o conhecimento" (PERRENOUD, 1999 apud BELLUZZO, 2013) está relacionado ao aprendizado ao longo da vida. Ao fazer a conexão com a informação propriamente dita, Belluzzo (2001) define Competência em Informação como:

Processo contínuo de interação e internalização de fundamentos conceituais, atitudinais e de habilidades específicas como referenciais à compreensão da informação e de sua abrangência, em busca da fluência e das capacidades necessárias à geração do conhecimento novo e sua aplicabilidade legal e ética ao cotidiano das pessoas e das comunidades ao longo da vida. 
A sociedade atual, conhecida como sociedade da informação e do conhecimento, preconiza que todas as pessoas, em todos os lugares, deverão ter acesso à informação como insumo básico para o desenvolvimento de sua vida pessoal e profissional. Uma das marcas mais contundentes desta era é a aceleração da produção e consumo de informação, impulsionados principalmente pelas tecnologias de comunicação cujo canal mais fortemente utilizado é a rede internet.

Desta forma, diante da imensidão de ofertas de informação à qual as pessoas em geral são submetidas todos os dias, percebe-se a necessidade cada vez mais presente de desenvolver habilidades em diferentes aspectos a fim de lidar com o excesso de informações em diferentes formatos.

Tais habilidades envolvem desde a capacidade de definir com clareza a existência de um problema informacional, passando pela competência em localizar, definir e acessar as melhores fontes de informação, além das habilidades cognitivas para compreender e assimilar conteúdos para resolver o problema e, ainda, ter a capacidade de gerar novas informações e conhecimentos a partir disso. De maneira especial, a etapa da localização, definição e acesso a fontes de informação abrange também a necessidade de ser hábil no uso de equipamentos e ferramentas tecnológicos.

Diferentes modelos foram criados com a finalidade de desenvolver competências, abrangendo vários aspectos aos quais deve-se dar atenção para que alguém possa ser considerado competente na busca, acesso e uso da informação. Dentre os mais conhecidos e utilizados, estão os seguintes (FURTADO; ALCARÁ, 2015):

- Big6Skill, proposto por Eisenberg e Berkowitz (1987) e voltado ao público estudante, tinha como foco a solução de problemas de informação com o uso de tecnologias e buscava desenvolver habilidades de localização, uso, aplicação e avaliação de informações para a realização de tarefas.

- Sete Pilares da Competência em Informação, elaborado pela Society of College National and University Libraries (SCONUL, 1999), combina habilidades, competências, atitudes e conhecimentos com o objetivo de identificar e examinar habilidades que formam a competência em informação;

- Empowering 8, desenvolvido pelo National Institute of Library and Information Sciences, no Sri Lanka em 2005, baseia-se na solução de problemas para aprendizagem e descreve oito habilidades relacionados a 38 resultados de aprendizagem referentes aos processos de busca e uso da informação. A criação deste modelo tem como contexto cultural as regiões Sul e Sudeste da Ásia e dirige-se aos estudantes da educação básica. 
Além dos modelos, existem padrões que auxiliam a criação e implementação de programas de CoInfo em diferentes contextos. Furtado e Alcará (2015, p.??) definem os padrões como “elementos norteadores e exercem a função de mediação das teorias, diretrizes e modelos apresentados com ações e programas para formação e desenvolvimento da Competência em Informação".

Dentre os padrões mais conhecidos, alguns são especialmente direcionados ao ambiente universitário, alvo da pesquisa em questão. Merece destaque o padrão criado pela American Library Association (ALA) em parceria com a Association of College and Research Libraries (ACRL). Trata-se de um elenco de 5 padrões (Necessidade, Acesso, Avaliação crítica, Uso e Ética) que possuem um conjunto de indicadores e seus respectivos resultados que definem um aluno universitário competente em informação.

Bruce (1997) aponta sete faces da competência em informação na educação superior, como resultado da experiência descrita por educadores em duas universidades australianas, apresentando-as em 7 categorias $^{2}$ :

Categoria 1: Concepção de informação tecnológica - A competência em informação aqui é vista como a capacidade de usar a informação para a recuperação da informação e para a comunicação. Nesta categoria, entende-se que a pessoa competente em informação é capaz de utilizar-se dos recursos tecnológicos para proceder uma 'varredura' nesse ambiente e atingir um alto nível de busca consciente da informação.

Categoria 2: Concepção das fontes de informação - A competência em informação permite encontrar a informação contida em fontes informacionais. Abrange o conhecimento de fontes de informação e a habilidade de acessá-las independentemente ou por meio de intermediários.

Categoria 3: Concepção da informação enquanto processo - A competência em informação se dá de forma processual. A esse processo correspondem as estratégias utilizadas pelos interagentes quando são confrontados por alguma situação onde precisam lidar com a falta de alguma habilidade, seja na busca ou na apropriação do conhecimento.

Categoria 4: Concepção do controle da informação - A pessoa competente em informação, nesta categoria, é capaz de armazenar a informação em diferentes mídias, de forma a facilitar seu acesso e uso.

\footnotetext{
competência em informação", publicado por Bruce em 1997.

${ }^{2}$ A autora faz uma relação dos resultados obtidos pela experiência dos educadores com o texto "As sete faces da 


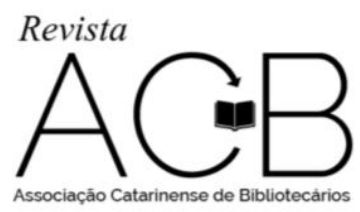

Revista ACB: Biblioteconomia em Santa Catarina, Florianópolis, v. 23, n. 1, p. 37-53, dez./mar., 2018.

Categoria 5: Concepção da construção do conhecimento - Aqui, o competente em informação é capaz de agregar novos conhecimentos a partir do uso crítico e avaliativo da informação.

Categoria 6: Conceito de conhecimento estendido - Neste conceito, o foco está na capacidade do competente em trabalhar o conhecimento e as perspectivas pessoais que dele advém, adotando seus insights de forma criativa à medida em que os adquire.

Categoria 7: Concepção da sabedoria - O competente em informação é capaz de usar a informação de maneira sábia em benefício de outras pessoas. Entram aqui as questões éticas e os valores pessoais que o uso crítico e competente de informações permitiu adquirir.

A contribuição de Bruce, por sua completeza e por dirigir-se especificamente à educação superior, foi escolhida para servir de base para a análise dos planos de ensino propostos pela pesquisa. Essas sete faces demonstram que, para além de um esforço cognitivo, ser competente em informação abrange aspectos ligados a habilidades que perpassam questões éticas para o uso da informação em benefício próprio e da sociedade.

Assim, percebe-se que a competência em informação é essencial para o desenvolvimento da capacidade crítica de análise e uso de informações para a tomada de decisão, sejam elas de cunho pessoal ou profissional. Por isso, pensar a competência em informação durante o ensino de graduação, de maneira geral, traz benefícios práticos ao aluno durante sua vida acadêmica e, de maneira específica aos futuros bibliotecários, possibilita um conhecimento técnico essencial para sua atuação profissional.

A CoInfo apresenta estreita ligação com o fazer bibliotecário e, portanto, deve fazer parte integrante dos conteúdos que fundamentam o ensino de Biblioteconomia. Para o presente estudo, a ênfase recai sobre a disciplina de Fontes de Informação, cujas conexões serão debatidas a seguir.

\subsection{COINFO E O ENSINO DE FONTES DE INFORMAÇÃO}

A quantidade torrencial de informações à qual um indivíduo é desafiado a administrar nos dias atuais (muitas das quais cuja qualidade é questionável) tornou-se um dos problemas que os profissionais da informação buscam resolver. Além disso, especialmente num contexto de grandes desigualdades sociais como o brasileiro, o acesso à informação ainda necessita ser facilitado desde bibliotecas infantis e escolares. A ênfase nesses casos, recai sobre o papel educacional do bibliotecário no contexto de uma oferta ainda precária de espaços e mecanismos adequados de acesso à informação em boa parte das escolas nos país. 


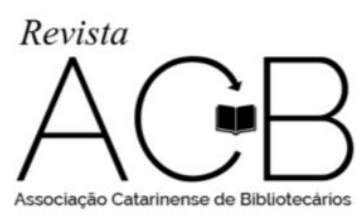

Revista ACB: Biblioteconomia em Santa Catarina, Florianópolis, v. 23, n. 1, p. 37-53, dez./mar., 2018.

Assim, a Competência em Informação apresenta-se como uma ferramenta de grande valor a ser utilizada em sua atuação dentro e fora das unidades de informação. Para que isto ocorra, faz-se necessário que o bibliotecário esteja consciente não apenas de seu papel social na orientação de leitores para a aquisição da competência em informação, mas também ele próprio seja competente diante dos desafios que a área informacional da sociedade contemporânea apresenta.

Gomes e Dumont (2015, p. 141) colocam em evidência a relação entre CoInfo e as fontes de informação quando afirmam que "o entendimento por parte dos indivíduos sobre fontes torna-se essencial para que eles possam utilizá-las a fim de satisfazerem suas necessidades de informação em quaisquer que sejam suas atividades".

O contexto informacional contemporâneo, marcado por um intenso fluxo de informação digital, oferece inúmeras oportunidades de acesso à informação, embora nem sempre de qualidade e, em muitos casos sem qualquer direção quanto ao como pode ser aplicada toda a massa informacional que está à sua disposição. Nesse cenário

O grande desafio é interagir com o fluxo informacional, que é dinâmico. Dessa forma, adquirir competência em informação é possuir um diferencial, pois a competência em informação é uma exigência na atual sociedade, marcada pela competitividade entre países, organizações e indivíduos. Questões como necessidade, acesso, localização e uso da informação são cruciais para quaisquer sociedades, principalmente para aquelas nas quais a indústria da informação não se encontra de forma consolidada. (GOMES; DUMONT, 2015, p. 141-142)

Por isso, o papel do bibliotecário enquanto educador torna-se imprescindível no processo de busca e uso desse material informacional. Toda a formação acadêmica do bibliotecário gira em torno do desenvolvimento de competências técnicas e profissionais que o tornam habilitado para atuar nos diferentes processos de informação, sejam eles voltados à gestão ou à mediação/educação para a busca, acesso e uso. Neste último, em especial, ficam evidenciadas suas habilidades no uso de fontes de informação em seus diferentes formatos e suportes:

As competências específicas da profissão do bibliotecário abrangem variados saberes relacionados ao tratamento e organização da informação. Sua formação pressupõe que ele tenha qualificação para o uso das fontes de informação disponíveis em todos os formatos e meios, sejam elas impressas e/ou multimídias, e que esteja preparado para a seleção, aquisição, tratamento, e disseminação da informação, recuperando-a quando necessário. E em razão desses saberes específicos que esse profissional é considerado o ideal para trabalhar na formação 
de habilidades relacionadas ao processo de uso das fontes de informação, isto é, da competência informacional. (MATA, 2009, p.81)

Campello e Abreu (2005) apontam as vantagens da inclusão do conceito de CoInfo nos cursos de Biblioteconomia e afirmam que

As experiências positivas vivenciadas pelos alunos na realização de trabalhos acadêmicos apontam para as vantagens da inclusão do conceito de competência informacional nos cursos de biblioteconomia. A ênfase em teorias e metodologias que fundamentam a aprendizagem da competência informacional e proporcionam oportunidades para exercitar a aprendizagem independente através de abordagens centradas no aluno, contribuirá para a formação de bibliotecários preparados para desempenhar sua função educativa. (op.cit, p.190)

As Diretrizes Curriculares Nacionais dos cursos de Biblioteconomia brasileiros apontam como uma das habilidades específicas exigidas na formação desse profissional "trabalhar com fontes de informação de qualquer natureza" (BRASIL, 2001, p. 32). Por este motivo, muitos cursos de graduação em Biblioteconomia apresentam em seus currículos a disciplina de Fontes de Informação, que tem por objetivos levar os alunos a conhecer e aplicar técnicas de busca, acesso, uso e avaliação de fontes de informação gerais e especializadas, impressas ou eletrônicas.

Em outras palavras, independente da carga horária que cada curso dedique à disciplina, das diferenças e semelhanças nas ementas e conteúdos programáticos delineados em cada universidade, podese afirmar que um objetivo comum entre essas disciplinas é tornar o futuro bibliotecário competente em informação. Embora visando desenvolver um conjunto de habilidades para o futuro desempenho de suas atividades profissionais, o ensino de Fontes de Informação apresenta benefícios igualmente ricos para a vida acadêmica dos alunos, bem como lhe oferece a possibilidade de utilizar esses conhecimentos para a construção de uma vida pessoal e cidadã qualitativamente melhor.

Por esses motivos, o tema ‘competência em informação' foi incluído no conteúdo programático do plano de ensino da disciplina oferecida em 2015/1 pelo curso de Biblioteconomia da FAED/UDESC.

\section{PROCEDIMENTOS METODOLÓGICOS}

A pesquisa teve caráter aplicado quanto aos seus objetivos. Segundo Prodanov e Freitas (2013) a pesquisa aplicada examina, descreve e avalia métodos e técnicas de pesquisa que proporcionam a coleta e o processamento de informações, visando à resolução das questões a serem investigadas. Quanto aos procedimentos, caracterizou-se como pesquisa bibliográfica, elaborada a partir de material já publicado, 


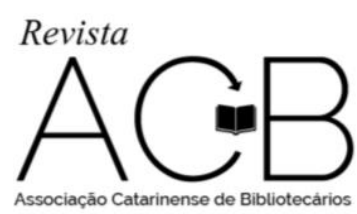

Revista ACB: Biblioteconomia em Santa Catarina, Florianópolis, v. 23, n. 1, p. 37-53, dez./mar., 2018.

com o objetivo de colocar o pesquisador em contato direto com todo o material já escrito sobre o assunto da pesquisa. (PRODANOV; FREITAS, 2013, p.54).

A pesquisa também assumiu caráter documental, na medida em que foi realizada análise comparativa entre a literatura específica sobre o tema e o plano de ensino da disciplina de Fontes de Informação oferecida no curso de graduação em Biblioteconomia da Universidade do Estado de Santa Catarina durante o ano de 2015. De acordo com Prodanov e Freitas (2013, p.55) a pesquisa documental "baseia-se em materiais que não receberam ainda um tratamento analítico ou que podem ser reelaborados de acordo com os objetivos da pesquisa."

Além disso, possuiu também caráter de pesquisa empírica por meio de observação sistemática, segundo seus procedimentos técnicos. na medida em que se utilizou da disciplina de Fontes de Informação para a aplicação de exercícios que permitissem apresentar o estado da arte e a evolução dos graduandos quanto à competência em informação na busca, acesso e uso de fontes de informação. O modelo utilizado foi o mesmo aplicado por Campello (2013) na disciplina Competência em Informação no curso de Biblioteconomia da UFMG.

A partir do levantamento bibliográfico realizado, deu-se a escolha do modelo de Bruce (1997), como a teoria mais adequada aos propósitos da pesquisa. Assim, procedeu-se análise documental a fim de identificar as conexões teóricas entre o modelo e o plano de ensino da disciplina de Fontes de Informação.

Para tal, foram analisadas as ementas, objetivos e conteúdos programáticos da disciplina identificando conceitos e termos que indicassem as possibilidades teóricas e práticas de aplicação dos pressupostos da Competência em Informação, relacionando-os a cada uma das sete faces apresentadas por Bruce.

Os resultados são apresentados a seguir, cuja discussão pretende atender aos seguintes objetivos específicos:

a) Identificação e análise de conexões teóricas entre os conceitos relativos à Competência em Informação e as ementas e conteúdos programáticos da disciplina, apresentando uma reflexão quanto às possíveis contribuições da introdução do tema na mesma;

b) Investigação sobre o potencial prático da aplicação do tema nas aulas de Fontes de Informação;

c) Aplicação de um modelo de Competência em Informação voltado ao ensino de graduação em Biblioteconomia a fim de verificar a real contribuição destes na formação acadêmica dos alunos de Biblioteconomia com vistas ao exercício de seu papel social enquanto educador e facilitador na geração de conhecimento. 


\section{CONEXÕES TEÓRICAS E PRÁTICAS ENTRE COINFO E FONTES DE INFORMAÇÃO}

A disciplina Fontes de Informação possui a seguinte ementa em seu plano de ensino: "Tipologias, características. Análise e avaliação de fontes de informação impressas ou eletrônicas. Domínio na utilização e orientação em fontes de informação gerais e especializadas. Produtores e provedores de bases de dados."

Apresenta como objetivo geral: "proporcionar aos acadêmicos as ferramentas necessárias para conhecer e avaliar fontes de informação gerais e especializadas, a fim de que possam exercer com segurança atividades em sua futura atuação profissional, sendo capazes de adquirir, pesquisar e auxiliar na pesquisa em fontes de informação impressas ou eletrônicas”.

A disciplina espera oferecer ao aluno ferramentas capazes de proporcionar aos acadêmicos o desenvolvimento de competências e habilidades para análise, avaliação, utilização, pesquisa e orientação para o uso de fontes de informação de diferentes tipologias e áreas do conhecimento, tanto gerais quanto especializadas, assim como impressas e eletrônicas.

Os verbos “conhecer”, “diferenciar”, “avaliar”, “analisar”, "recuperar” e “identificar” são recorrentes em quase todos os itens do plano de ensino. As palavras "domínio" e "segurança" são mencionadas como finalidades da disciplina ao preparar o aluno para exercer "sua futura atuação profissional". Ressalta-se o caráter técnico da competência em informação, buscando uma formação acadêmica que lhe garanta sucesso no uso de fontes de informação enquanto bibliotecário.

A leitura dos planos de ensino sob o ponto de vista de suas conexões a partir das sete categorias da competência em informação na educação superior apresentadas por Bruce (1997), permitiu estabelecer as seguintes correlações entre a disciplina de Fontes de Informação e a CoInfo encontradas na maioria dos conteúdos abarcados nas sete categorias, uma vez que:

a) Direciona suas atenções no sentido de facilitar ao acadêmico o desenvolvimento de sua capacidade de usar a informação para a recuperação e comunicação da mesma, esta subentendida enquanto atuação profissional. Oferece condições para o uso de recursos tecnológicos e técnicos de busca, acesso e análise tanto no ambiente físico quanto eletrônico;

b) Possibilita o conhecimento das fontes de informação tanto em seus aspectos conceituais, históricos e organizacionais quanto nos processos de construção do conhecimento e da habilidade de acesso independente e autônomo;

c) Proporciona desenvolver o domínio na utilização e orientação para o uso de fontes pressupõe a aquisição de habilidades de controle de registros para usos futuros, bem como a capacidade de 
rastrear a informação em diferentes tipos de fontes de informação, indicando habilidade de controle de termos e descritores para a busca;

d) O desenvolvimento dos conteúdos do programa da disciplina supõe a concepção da construção de um conhecimento técnico e do uso crítico e avaliativo da informação a fim de obter a recuperação da informação necessária de forma precisa e, assim, permitir que o aluno agregue conhecimentos com a finalidade de auxiliar outras pessoas no desenvolvimento de sua competência em informação.

Para conhecer as conexões práticas, foram realizados exercícios com os alunos matriculados na disciplina de Fontes de Informação ministrada em 2015/1 cujos resultados são apresentados a seguir. A escolha da aplicação nessa disciplina baseia-se no fato de que a CoInfo, apesar de não estar prevista de maneira formal, é parte integrante de seu conteúdo programático a partir de 2015. Assim, foram propostos exercícios complementares que pudessem indicar se os alunos de Biblioteconomia apresentam indícios de uma prática competente na localização, acesso e uso de fontes de informação para a solução de problemas.

Os exercícios consistiram numa adaptação da experiência apresentada por Campello (2013) no capítulo cinco do livro "Competências em Informação: de reflexões às lições aprendidas”, organizado por Belluzzo e Feres (2013). O capítulo, sob o título “A disciplina Competência Informacional no currículo do curso de Biblioteconomia da Escola de Ciência da Informação da UFMG: compromisso com a função educativa do bibliotecário", apresenta o relato de Campello enquanto professora da disciplina que possui carga horária de 30 horas/aula e é oferecida na quinta fase do curso.

A autora descreve a dinâmica de aula da disciplina com atividades "em espiral, segundo o qual a aprendizagem se dá quando o estudante revisita as mesmas áreas do conhecimento várias vezes e, a cada vez, atinge um nível maior de compreensão" (CAMPELLO, 2013, p.130). Campello descreve a estrutura da disciplina, organizada em sete encontros de quatro horas e mais um de duas horas, completando a carga horária total, apresentando detalhes de cada um desses encontros, cujos pontos principais que foram adaptados para a aplicação nesta pesquisa são destacados a seguir:

a) Apresentação da questão a ser pesquisada no primeiro encontro, a partir de diálogo aberto entre professor e alunos deixando claros os objetivos da atividade;

b) Necessidade de descrição das estratégias de busca e fontes utilizadas para a pesquisa; 
c) Em encontros seguintes, os alunos retornam com os resultados das atividades, relatam dificuldades e recebem orientações quanto à próxima etapa a ser realizada, aprofundando o tema de pesquisa com novas questões e novas estratégias de busca;

d) A etapa final, de apresentação e análise do processo ocorrido durante a disciplina, pretende enfatizar a experiência vivida pelos alunos e refletir sobre o papel educador do bibliotecário.

Levando em consideração que a disciplina objeto desta pesquisa dedica-se ao desenvolvimento de atividades próprias de áreas de atuação com as quais a CoInfo pode contribuir, e não à competência em informação propriamente dita, o tempo dedicado ao desenvolvimento dos exercícios foi significativamente menor do que o utilizado por Campello em sua experiência.

Desta forma, a aplicação adaptada da metodologia de aula apresentada por Campello consistiu em apenas três encontros: um ao início do semestre no qual o exercício foi proposto, um segundo na semana seguinte para a primeira apresentação dos resultados e outro ao final do semestre, a fim de avaliar possíveis evoluções no processo. O relato e resultados desses exercícios são apresentados a seguir.

As aulas da disciplina de Fontes de informação iniciaram em 20 de fevereiro de 2015, com 25 alunos matriculados. A fim de contextualizar os alunos quanto às conexões da COINFO com a disciplina, o tema foi abordado de forma teórica com apresentação dos principais conceitos e do processo que o envolve já no segundo dia de aula do semestre, dia 27 de fevereiro. Após breve discussão sobre o tema e elaboração coletiva de um mapa conceitual introdutório sobre CoInfo, foi proposto o exercício com a seguinte questão a ser respondida: 'Existe consenso sobre o conceito de informação'?

A ideia de propor o exercício no início da disciplina buscou identificar nos alunos indícios da formação de uma competência voltada ao acesso e uso da informação a partir de seus conhecimentos prévios voltando a aplicá-lo ao final do semestre e, assim, obter uma visão mais concreta do potencial da conexão da CoInfo com o desenvolvimento da disciplina.

Para a realização da pesquisa e responder à questão, foi esclarecido que os alunos deveriam buscar um artigo ou capítulo de livro sobre o tema, explicando quais estratégias de busca foram utilizadas e quais fontes de informação foram consultadas. Também deveriam ler e resumir o texto escolhido para debater as respostas encontradas no próximo encontro, marcado para o dia seis de março, na semana seguinte.

O segundo encontro ocorreu na data marcada, quando os alunos tiveram a oportunidade de relatar sua experiência e apresentar o resultado encontrado para a solução da questão proposta nos textos escolhidos para leitura. Apenas 10 alunos retornaram com o exercício feito, sob alegações de esquecimento ou de ausência na aula anterior.

Quanto às estratégias de busca, os resultados foram os seguintes: 
a) A totalidade dos alunos iniciou sua busca a partir da ferramenta Google, usando a própria pergunta formulada pela professora, ou partes dela;

b) A maioria fez a busca sem a aplicação de filtros, houve apenas um relato do uso de aspas e outro sobre o acréscimo do termo "artigo acadêmico" aos termos de busca;

c) Apenas duas menções da escolha de monografias para a leitura, os demais escolheram artigos científicos;

d) Nenhum relato sobre o uso dos recursos de bibliotecas.

Quanto à resposta da pergunta, o retorno foi ainda menos satisfatório: apenas quatro acadêmicos puderam debater o tema a partir dos resultados de suas buscas. Houve uma menção em relação à leitura de uma dissertação sobre o tema, com a conclusão de que a resposta à pergunta 'existe consenso sobre o conceito de informação' é negativa. Quanto aos demais, foram citados Moresi3 (uma menção) afirmando a possibilidade de consenso e Capurro4 (duas menções), um dos mais importantes autores que discutem o tema na área da Ciência da Informação, concluindo não haver consenso para o conceito de informação. Os demais não trouxeram dados precisos sobre a leitura ou puderam se posicionar quanto à resposta.

Estes primeiros resultados demonstraram a inexperiência dos alunos e uma incipiente capacidade de acessar e utilizar a informação com a finalidade de solucionar um problema específico de informação. Na oportunidade, foram ressaltados os objetivos da disciplina de Fontes de Informação, dando destaque à característica formativa na aprendizagem de estratégias e técnicas de busca e apresentação de diferentes fontes de informação para além do uso do Google enquanto buscador principal na internet.

O terceiro encontro com a finalidade da pesquisa aconteceu ao final do semestre, na data de 19 de junho de 2015. Na semana anterior, os alunos foram novamente desafiados a responder à pergunta feita no início do semestre, devendo novamente indicar as estratégias de busca e fontes utilizadas, bem como fazer a leitura de um texto de livre escolha para o debate.

Desta vez, 18 alunos retornaram com suas pesquisas feitas, tendo sido relatadas buscas nas seguintes fontes de informação: bases de dados Scielo e BRAPCI; Biblioteca Digital de Teses e Dissertações (BDTD - IBICT); Portal de Periódicos da CAPES. Houve menção de buscas no Google Acadêmico, em blogs da área de Ciência da Informação e um relato de estabelecimento de um diálogo com professores estudiosos da área para conhecer sua opinião a respeito. Quanto às estratégias de busca, foram relatados o uso de filtros, busca simples e busca avançada; e operadores booleanos.

\footnotetext{
${ }^{3}$ Eduardo Amadeu Dutra Moresi, doutor em Cl pela UnB

${ }^{4}$ Rafael Capurro, filósofo da informação e professor uruguaio

Revista ACB: Biblioteconomia em Santa Catarina, Florianópolis (Brasil) - ISSN 1414-0594 


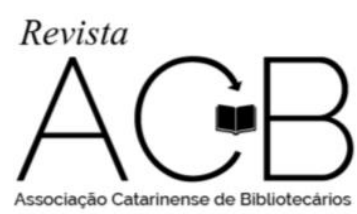

Revista ACB: Biblioteconomia em Santa Catarina, Florianópolis, v. 23, n. 1, p. 37-53, dez./mar., 2018.

As palavras chave mais utilizadas foram conceito e informação; os autores Capurro e Araújo ${ }^{5}$ foram apontados como os mais citados nas pesquisas e, para a maioria dos alunos, a resposta ao questionamento inicial que motivou a busca é de que não há consenso sobre o conceito de informação.

Diante desses resultados, é possível afirmar que a disciplina de Fontes de Informação permitiu aos alunos ampliarem o leque de possibilidades de busca em diferentes fontes de informação, desde pessoas e blogs especializados na área do assunto em tese, até bases de dados e portais de periódicos. O refinamento nas estratégias de busca também foi percebido, tendo sido constatada uma maior autonomia e propriedade no uso de descritores e dos recursos oferecidos em cada fonte.

No entanto, destaca-se novamente que não houve menção ao uso dos recursos da biblioteca. Merece atenção também que apenas fontes e textos em português foram utilizados, além do fato de que a ferramenta Google foi mais uma vez mencionada por metade dos alunos que fizeram o exercício (nove menções).

\section{CONSIDERAÇÕES FINAIS}

A aplicação de modelos de competência em informação no ensino superior permite que o aluno desenvolva habilidades para o acesso e assimilação da informação de maneira mais eficiente e crítica, construindo o conhecimento necessário à sua formação acadêmica e profissional.

No caso específico do curso de Biblioteconomia, verificou-se que a aplicação da CoInfo ultrapassa esses objetivos na medida em que também o prepara para ser um multiplicador nessa formação em sua atuação futura. Além de competente em informação, o futuro bibliotecário terá condições de atuar como mediador no processo de desenvolvimento de habilidades para a busca, acesso, assimilação da informação a fim de solucionar problemas e de construir um ambiente de geração e transmissão de conhecimentos junto à comunidade de sua unidade de informação.

Em relação aos usos teóricos, percebeu-se ume estreita relação entre o plano de ensino e as categorias de CoInfo apresentadas por Bruce, atestando que os conteúdos propostos encontram-se concatenados com o modelo da autora.

Os resultados dos exercícios foram discutidos em sala com os alunos, tendo sido verificado um sensível amadurecimento destes em relação ao seu comportamento na busca de informações. Por outro

\footnotetext{
${ }^{5}$ Carlos Alberto Ávila Araújo, doutor em Ciência da Informação e diretor da Escola de Ciência da Informação da Universidade Federal de Minas Gerais 
lado, ressalta-se a necessidade de incentivar e promover o uso dos estoques informacionais de bibliotecas como recurso de pesquisa, uma vez que estas não foram mencionadas no relato dos acadêmicos.

Pode-se afirmar que aplicação prática dos modelos de CoInfo, a partir de exercícios de uso de fontes de informação, confirma o valor da introdução do tema na formação do acadêmico, pois os resultados demonstram a necessidade de um investimento maior no desenvolvimento da competência em informação visando uma atuação profissional para a mediação no desenvolvimento dessas habilidades junto à comunidade de interagentes em unidades de informação.

Os resultados permitiram atingir o objetivo da pesquisa, identificando a existência de conexões entre os modelos de CoInfo e a disciplina de Fontes de Informação e indicando que o uso teórico e prático desses modelos em sala de aula instrumentaliza os graduandos para uma busca, acesso e uso de fontes de informação de maneira mais competente tanto para sua vida acadêmica como para sua futura atuação profissional.

Desta forma, percebe-se que tais conexões entre o tema e a disciplina analisada podem abrir caminhos para uma reflexão mais atualizada do papel do bibliotecário enquanto curador e mediador da informação com vistas a uma melhor compreensão de seu papel social também enquanto educador. Essa disciplina, pois, apresenta-se como um campo fértil para a aplicação de modelos de CoInfo pois está intimamente relacionada às suas etapas e processos, confirmando as hipóteses levantadas pela pesquisa.

Por fim, acredita-se que a aplicação da CoInfo na disciplina de Fontes de Informação do curso de graduação em Biblioteconomia, auxiliará na formação de um profissional competente em informação, inserido de forma crítica e consciente, que poderá se transformar em um ator importante na construção de uma sociedade melhor informada e, portanto, com maior qualidade de vida.

\section{REFERÊNCIAS}

BELLUZZO, Regina Célia Batista. A information literacy como competência necessária à fluência científica e tecnológica na sociedade da informação: uma questão de educação. In: SIMPÓSIO DE ENGENHARIA DA PRODUÇÃO DA UNESP, 7., 2001. Anais. São Paulo: UNESP, 2001. Disponível em: <http://www.simpep.feb.unesp.br/ana8.html> Acesso em 02 jul. 2017.

BELLUZZO, Regina Célia Batista, FERES, Glória Georges. (Orgs.) Competência em Informação: de reflexões as lições aprendidas. São Paulo: FEBAB, 2013. Disponível em: <https://issuu.com/necfciunb/docs/compet_ncia_em_informa____de_re> Acesso em: 02 jul. 2017. 
BRASIL. Ministério da Educação. Diretrizes Curriculares Nacionais dos cursos de Filosofia, História, Geografia, Serviço Social, Comunicação Social, Ciências Sociais, Letras, Biblioteconomia, Arquivologia e Museologia, 2001. Disponível em:

<http://portal.mec.gov.br/cne/arquivos/pdf/CES0492.pdf > . Acesso em: 18 jul. 2017.

BRUCE, Christine. Seven faces of information literacy in higher education. Brisbane: QUT, [1997].

Disponível em: <http://sky.scitech.qut.edu.au/ bruce/inflit/faces/faces1.htm>Acesso em: 20 jul. 2017.

CAMPELLO, Bernadete dos Santos, ABREU, Vera Lúcia Furst Gonçalves. Competência informacional e formação do bibliotecário. Perspectivas em Ciência da Informação, Belo Horizonte, v.10 n.2, p. 178193,jul./dez. 2005. Disponível em:

<http://portaldeperiodicos.eci.ufmg.br/index.php/pci/article/view/2/150> Acesso em: 02 jul. 2017.

CAMPELLO, Bernadete dos Santos. O movimento da competência informacional: uma perspectiva para o letramento informacional. Ciência da Informação, Brasília, v.32, n. 3, p.28-37, set./dez.2003.

Disponível em: <http://www.scielo.br/scielo.php?script=sci_abstract\&pid=S010019652003000300004\&lng=pt\&tlng=pt> Acesso em: 02 jul. 2017.

FURTADO, Renata Lira; ALCARÁ, Adriana Roseclér. Desenvolvimento e formação de competência em informação: um mapeamento de modelos, padrões e documentos. IN: ENCONTRO NACIONAL DE PESQUISA EM CIÊNCIA DA INFORMAÇÃO, 16., 2015, João Pessoa. Anais... João Pessoa: UFPB, 2015. Disponível em:

<http://www.ufpb.br/evento/lti/ocs/index.php/enancib2015/enancib2015/schedConf/presentations> Acesso em: 18 jul.2017.

GOMES, Marco Aurélio; DUMONT, Lígia Maria Moreira. Possíveis relações entre o uso de fontes de informação e a competência em informação. Transinformação, Campinas, v. 27, n.2, maio/ago. 2015. Disponível em: < http://www.scielo.br/pdf/tinf/v27n2/0103-3786-tinf-27-02-00133.pdf> Acesso em: 18 jul. 2017.

MATA, Marta Leandro da. A competência informacional de graduandos de Biblioteconomia da região sudeste: um enfoque nos processos de busca e uso ético da informação. Dissertação (Mestrado em Ciência da Informação) - Faculdade de Filosofia e Ciências, Universidade Estadual Paulista, 2009. Disponível em: <https://www.marilia.unesp.br/Home/Pos-

Graduacao/CienciadaInformacao/Dissertacoes/mata_ml_me_mar.pdf $>$ Acesso em: 17 jul. 2017

PRODANOV, Cleber Cristiano; FREITAS, Ernani Cesar de. Metodologia do trabalho científico: Métodos e Técnicas da Pesquisa e do Trabalho Acadêmico. 2. ed. Novo Hamburgo: Feevale, 2013. 277 p. Disponível em: <https://www.feevale.br/cultura/editora-feevale/metodologia-do-trabalhocientifico---2-edicao> . Acesso em: 27 jun. 2017. 


\section{ELISA CRISTINA DELFINI CORRÊA}

Doutora em Sociologia Política pela Universidade Federal de Santa Catarina (UFSC).

Mestre em Sociologia pela Universidade Federal de Santa Catarina (UFSC).

Graduada em Biblioteconomia pela Universidade do Estado de Santa Catarina (UDESC).

Docente do Departamento de Biblioteconomia e Gestão da Informação - DBI/FAED/UDESC e do

Programa de Pós-Graduação em Gestão da Informação - PPGINFO/FAED/UDESC

R. Madre Benvenuta, 2007 - Itacorubi - Florianópolis - SC

$48-984024499$

elisacorrea61@gmail.com

\section{RECEBIDO EM: 04-10-2017}

ACEITO EM: 14-03-2018 